\title{
A Interação Entre Produtores e Usuários de Plásticos como Instrumento de Competitividade
}

\begin{abstract}
O Núcleo de Reologia e Processamento de Polímeros do Departamento de Engenharia de Materiais da Universidade Federal de São Carlos promoveu, em março último, o I Seminário Brasileiro sobre Avanços em Processamento de Polímeros, motivando a troca de experiências para a identificação e solução dos problemas que atingem fabricantes de máquinas e de resinas, componedores, transformadores e usuários de produtos finais de materiais plásticos. Seis palestras e três debates suscitaram discussões que evidenciaram a necessidade urgente de diálogo e - principalmente - de cooperação entre os diferentes setores. A presente matéria tem por objetivo apresentar de forma sucinta alguns dos problemas discutidos, complementados por informações obtidas posteriormente junto à comunidade..
\end{abstract}

A reunião de fabricantes de máquinas e de compostos, de transformadores e usuários finais durante o I Seminário Brasileiro sobre Avanços em Processamento de Polímeros, permitiu a cada segmento apresentar as dificuldades do dia a dia a seus parceiros comerciais. Fornecedores e consumidores puderam colocar suas dificuldades e avaliaram sua posição dentro de um mercado globalizado, com exigência premente de qualidade, produtividade e menor custo. Apesar de ter reunido cerca de 270 pessoas, o seminário não teve uma participação numericamente expressiva de médios e pequenos transformadores e usuários de plástico, o que não impediu que muitas discussões girassem em torno de suas necessidades.

\section{Matéria-prima versus Custo}

Mesmo ainda tendo alguns problemas com envelhecimento precoce, a matéria-prima nacional é de boa qualidade, equivalente à de primeiro mundo. A maior dificuldade, a nível de competitividade, tem sido seu custo em relação ao mercado internacional, o que pode ser facilmente compreendido quando se atentar para a capacidade de produção do Brasil. Tomando-se como exemplo o ABS desde a fase de polimerização, granulação e comercialização, verificamos que os dois grandes produtores nacionais Nitriflex e Bayer - produzem, no total, de 80 a 100 mil toneladas/ano, enquanto que a Chi Mei produz 1 milhão de toneladas de ABS e SAN e a Samsung produz $600 \mathrm{mil}$ ton/ ano. O custo passa a estar diretamente relacionado com um problema sério, que é a escala de produção. $\mathrm{O}$ que os produtores nacionais podem fazer para competir com esses grandes produtores é justamente o grande problema a ser resolvido. A escala também tem motivado algumas empresas a importarem componentes para seus produtos, tanto em função do custo quanto da confiabilidade dos fornecedores.

O baixo custo da matéria-prima sem dúvida é um grande incentivo para a importação, sobretudo quando não se conta com a possibilidade de algumas surpresas adicionais, como algum problema com transporte ou com a assistência técnica. Alguns casos recentes demonstraram que $o$ barato pode não ser tão compensador assim, sendo recomendável manter também um fornecedor local.

No Brasil é muito comum - na verdade é quase um vício - a escolha de um determinado material apenas em função de seu preço. Quase ninguém se dá ao trabalho de fazer uma análise mais detalhada dos custos, avaliando previamente todas as etapas do processo decorrentes da seleção de um ou outro material, até se chegar ao custo do produto final. A utilização de uma determinada resina ou uma mudança no projeto do maquinário de processamento podem alterar algumas etapas do processo, acrescentando custos, de 
tal forma que a utilização de um material, em princípio mais barato que outro, acaba tornando o produto mais caro no seu final. Durante o Seminário de Avanços em Processamento de Polímeros foram apresentados alguns exemplos bastante interessantes. Um deles fazia a simulação do custo de um painel de carro com a utilização de duas resinas, uma importada e outra nacional. Para esse estudo foram considerados diversos itens como o volume da peça, a densidade e a quantidade de resina necessária, o custo da matéria-prima e as etapas de pré-processamento. E foi exatamente ao se chegar nesse ponto que a resina importada, e mais barata, começou a perder terreno para a nacional que, ao contrário de sua concorrente importada, não precisava de secagem. A resina nacional não precisava de secagem, portanto não havia custo do secador e nem o da mão de obra. O ciclo de injeção era menor e trazia ganhos de produtividade. Feitas todas as contas, verificou-se que a utilização da resina nacional tornava o painel mais barato e com ganho de produtividade, mesmo com um custo superior ao da matéria-prima importada. Outro fator importante para a redução dos custos é a escolha correta do material a ser utilizado em função da finalidade ou da utilização do produto final. Algumas empresas não tomam os cuidados necessários, talvez até por falta de conhecimento das características dos materiais, escolhem de forma inadequada e depois têm de arcar com um prejuízo que acaba com toda possibilidade de competitividade.

Não menos séria é a qualificação de empresas apenas em função do preço, sem se considerar a qualidade de seus produtos, baseada num critério rigoroso de seleção de materiais. Muitas empresas têm sido qualificadas por seus clientes apenas pelo preço, devido à absoluta falta de preparo das pessoas encarregadas de fazer essa qualificação, as quais não conseguem avaliar a importância da qualidade dentro de um mercado globalizado.

\section{A globalização a médio e longo prazo}

Se considerarmos que a reserva de mercado, existente até há bem pouco no Brasil, há muito tinha seus dias contados, veremos que ela foi realmente benéfica para os setores que aproveitaram esse período para investir em tecnologia. $\mathrm{Na}$ área das telecomunicações, por exemplo, de 1976 a 1990 foi feita a substituição dos importados, desenvolveu-se o parque industrial e foram criados pólos tecnológicos, com grande desenvolvimento de produtos e também muitas transferências tecnológicas para que as empresas pudessem crescer e ter oportunidade de mercado. Em outros setores, porém, muitas empresas apenas colheram os frutos imediatos da reserva de mercado, não levando a sério todas as mudanças que viriam com a globalização e hoje estão amargando essa competição com o mercado globalizado. Com o pouco que se investiu, houve um atraso muito grande em matéria-prima, em reciclagem de mão-de-obra, em tecnologia de processos. No setor automobilístico, por exemplo, simultaneamente ao advento dos carros mundiais, surgiram os fornecedores globais. A globalização trouxe novas oportunidades tecnológicas e também o grande desafio para os fornecedores locais de auto-peças: o de oferecer os mesmos benefícios que seus concorrentes do exterior. Muitas empresas até conseguiram se associar a grupos estrangeiros, porém como isso não será possível para todos, a rapidez com que os pequenos e médios fornecedores locais consigam se equiparar a seus concorrentes será um dos mais importantes fatores de sobrevivência dentro desse novo mercado.

Não se pode negar que a globalização foi o fator que levou a indústria de transformação, de produção de resinas e de máquinas a buscar soluções realmente competitivas, através de mudanças estruturais muito fortes, numa renovação do parque produtivo. Qualidade, serviços e preços são as palavras de ordem. A nível de qualidade, há a busca incessante do "zero defeito", com a mobilização das empresas para a padronização dos seus sistemas de controle, de produção e de qualidade, através da implantação da ISO 9000. O Brasil teve um grande número de empresas certificadas em pouquíssimo tempo, em comparação com os Estados Unidos e o Japão. Na área de serviços têm sido adotadas técnicas e ferramentas japonesas, "just in time", resoluções técnicas, enfim, um conjunto de ações visando ao enxugamento da estrutura organizacional. As exigências de qualidade são bastante rígidas e estão se afunilando de tal forma que os transformadores terão de utilizar todos os recursos possíveis para se manter dentro desse novo mercado. Observa-se, às vezes, uma certa apatia por parte de algumas empresas de transformação de plástico, como se estivessem à espera de uma atitude paternalista do mercado, que as colocaria a salvo 
da acirrada concorrência internacional. Na verdade a questão é muito mais séria: as melhores empresas nacionais estão sendo compradas por grandes grupos estrangeiros, enquanto as demais ficam à deriva, entregues à própria sorte, até finalmente quebrarem por falta de condições de qualidade, preço e competitividade.

Os fabricantes de máquinas sofrem tanto com a concorrência do exterior quanto com o "Custo-Brasil". Na última Brasilplast, em março, os asiáticos faziam marcação corpo a corpo com os brasileiros. As máquinas vêm de fora a preços muito inferiores e com financiamento. A qualidade é boa, mas o equipamento é descartável, mas mesmo assim o custo baixo compensa a vida curta da máquina, principalmente para quem não tem muito dinheiro. Se o mercado internacional mantiver o atual nível de agressividade, com um pouco mais de tempo a indústria nacional pode ficar em situação realmente difícil.

Há uma necessidade imperiosa de se buscar soluções realmente criativas a curtíssimo prazo. $\mathrm{O}$ extraordinário desenvolvimento dos tigres asiáticos nas duas últimas décadas é um exemplo que, se não pode ser adotado, ao menos deve merecer uma séria reflexão e servir de incentivo para a solução de nossos problemas.

\section{Buscando soluções}

A utilização de modernas técnicas computacionais não tem sido plenamente utilizada no Brasil, na medida em que não existe a devida caracterização das matérias-primas nacionais. Os softwares são tão mais eficazes quanto mais precisos forem os parâmetros inseridos nele.
Comumente são adotadas matériasprimas equivalentes às que constam no banco de dados do software, em função da indisponibilidade da matéria-prima nacional. Seria muito importante que os fabricantes nacionais buscassem a homologação de seus produtos para que viessem a fazer parte desse banco de dados, o que facilitaria bastante a vida de seus clientes. Por enquanto parece não haver um interesse muito forte em se gerar dados suficientes sobre caracterização reológica e mecânica de resinas nacionais, para gerar um banco de dados que dê confiabilidade aos programas de simulação de fluxo no processamento (moldflow, por exemplo), às análises estruturais e na avaliação de desempenho mecânico de peças técnicas de plásticos.

Durante o Seminário de Avanços em Processamento de Polímeros observou-se que as condições de processamento não têm sido devidamente consideradas dentro do contexto de produtividade. Quase nenhuma atenção é dada à adequação entre máquina e matéria-prima e cerca de $90 \%$ dos transformadores usam roscas universais para processamento dos mais diferentes tipos de materiais, como PE, PP e outros. A adequação rosca/matériaprima pode acarretar ganhos de produtividade de até $20 \%$, principalmente no processamento das resinas mais utilizadas pela indústria automobilística. Muitos transformadores conhecem os benefícios da rosca de duplo filete, mas não a usam por não terem uma idéia exata da diferença entre custo e investimento. A utilização da rosca adequada para o processamento de um determinado material não só vai diminuir o custo do produto e as perdas, como vai aumentar a produtividade e isso tem que ser considerado como investi- mento e não simplesmente como custo. Não se pode focalizar a atenção apenas na compra em si, mas no que ela vai representar a médio e longo prazo, a nível de produtividade e competitividade dentro do mercado.

\section{Formação e Reciclagem de RH}

Estima-se que $95 \%$ das empresas transformadoras de plástico não têm um profissional técnico de grau superior em seus quadros e essa falta de funcionários com formação adequada é um dos mais importantes fatores que limitam a evolução das empresas e que dificultam a interação produtor-consumidor. Não adianta melhorar máquinas, roscas ou resinas, se o profissional responsável pela otimização das condições operacionais da máquina de processamento não tiver a capacitação necessária. Palavras como viscosidade e torque são desconhecidas de muitos transformadores. Durante o período de reserva de mercado, o investimento em recursos humanos foi mínimo e, com o advento da globalização e o enxugamento da estrutura das empresas, os funcionários que ficaram passaram a ser mais solicitados, com aumento das responsabilidades e da carga de trabalho, sem receber como contrapartida uma preparação adequada para isso.

Os fabricantes de matéria-prima têm conhecimento dessas dificuldades e procuram minimizá-las, oferecendo toda uma assistência técnica de suporte, além de uma série de serviços oferecidos graciosamente. É muito comum a distribuição de catálogos técnicos com informações sobre propriedades físicas ou processabilidade das resinas poliméricas ou dos seus compostos, 
porém também é muito comum que toda essa literatura esteja muito além da capacidade de assimilação do pessoal que hoje está trabalhando com plástico, ou que os catálogos fiquem guardados na gaveta do comprador da empresa e não cheguem às mãos de quem precisaria ter a informação. Há então dois problemas: a forma de se passar a informação e como fazê-la chegar à pessoa certa.

A indústria de tintas conseguiu reduzir erros grosseiros na pintura de peças, fazendo uma aproximação com o processador final, a quem oferece cursos rápidos dentro da indústria. Empresas como Polibrasil, OPP e Politeno mantêm contato direto com muitos de seus clientes, orientando-os em questões de qualidade, equipamentos e produtividade; oferecendo treinamento e serviços de laboratório para análises e caracterização. Poucos porém são os beneficiados, em vista do universo de clientes que têm. $\mathrm{Na}$ verdade, o cliente que usa um produto muitas vezes não tem a informação dos recursos que a empresa disponibiliza para atendêlo. Todas as empresas petroquímicas dispõem nas suas unidades de laboratórios de desenvolvimento e, independente do laboratório de controle de qualidade, possuem laboratórios de produtos e de assistência técnica. Elas sabem que seus clientes não têm condições, e nem necessidade, de manter todo um corpo técnico para fazer análises esporádicas e coisas do tipo.

A iniciativa de cursos de treinamento oferecidos por instituições como a ABPol - Associação Brasileira de Polímeros e o INP - Instituto Nacional do Plástico não tem conseguido atingir adequadamente as pequenas e médias empresas transformadoras, mas tão somente as grandes, que já têm uma cultura em formação de recursos humanos. O desafio não é tanto descobrir como motivar os diretores das empresas de transformação a investir em treinamento para a capacitação de seus funcionários a curto prazo mas, sobretudo como conscientizá-los da necessidade desse tipo de investimento. $\mathrm{O}$ profissional a quem se oferece uma formação básica tem muito mais condições de assimilar as mudanças tecnológicas, operacionais e gerenciais necessárias à competitividade de sua empresa. Ignorar essa situação só vai trazer prejuízos ainda maiores, talvez até irremediáveis. O "milagre" dos tigres asiáticos não aconteceu por acaso. A falta de formação adequada e de reciclagem de conhecimentos dos profissionais é um dos mais sérios problemas a serem resolvidos para se chegar ao nível da competitividade internacional. As exigências de qualidade hoje são bastante rígidas, e os transformadores terão de se adaptar a elas, sob pena de ficar fora do mercado.

\section{Procurando a saída}

O grande desafio da indústria nacional do plástico hoje é encontrar meios de tornar os produtos nacionais internacionalmente competitivos. Os produtores dos plásticos de engenharia não têm escala e seus preços sofrem acirrada concorrência. Os transformadores não têm suficiente qualidade e competitividade. Os fabricantes de máquinas têm concorrentes muito fortes. Acrescente-se a isto a carência de recursos humanos especializados e as dificuldades de interação entre produtores de matéria-prima, de equipamentos e transformadores. Quantas empresas de plástico foram adquiridas por grupos estrangeiros nos últimos dois anos?

Existe saída? Se existir, o caminho só pode ser um: o da interação entre produtores de matérias-primas e compostos, fabricantes de máquinas e equipamentos, transformadores e usuários finais. Mesmo as grandes empresas, com boa posição no mercado, defendem a necessidade de soluções conjugadas, da união de esforços, num sinergismo único que trará custos competitivos aos produtos finais, que é o que interessa aos usuários. As empresas brasileiras têm que descobrir como trabalhar em parceria, desde o desenvolvimento do produto, visando um custo final competitivo, principalmente com os importados.

As entidades setoriais devem procurar canalizar a interação entre os diversos segmentos, promovendo o diálogo entre as partes e fazendo fluir as informações. Devem ser mantidos fóruns de debates para a troca de experiências e a busca de soluções, até que a indústria, como um todo, tenha as condições de qualidade, produtividade e competitividade exigidas pela abertura do mercado.

Sensível a esta situação, a Associação Brasileira de Polímeros estará realizando em 29 de julho próximo a reunião inaugural da Comissão Técnica de Reologia e Processamento de Polímeros, dando assim continuidade às discussões iniciadas com o I Seminário Brasileiro sobre Avanços em Processamento de Polímeros, promovido pelo Núcleo de Reologia e Processamento de Polímeros do Depto. de Engenharia de Materiais da UFSCar. A participação estará aberta a todos os interessados. Solicitar informações adicionais à secretaria da ABPol pelo telefax 016 274.3949. 